J-ABDIPAMAS (Jurnal Pengabdian Kepada Masyarakat)

Vol. $3 \bullet$ No. $2 \bullet 2019$

ISSN : 2581-1320 (Print) ISSN : 2581-2572 (Online)

Homepage: http://ejurnal.ikippgribojonegoro.ac.id/index.php/J-ABDIPAMAS

\title{
ENTREPRENEURSHIP DALAM LINGKUNGAN SEKOLAH DI SMA PGRI 4 PALEMBANG
}

\author{
Neta Dian Lestari1 ${ }^{1}$ Diana Widhi Rachmawati², Erma Yulaini ${ }^{3}$, Nova Pratiwi ${ }^{4}$, \\ Ida Suryani ${ }^{5}$, Chandra Kurniawan 6 , Januardi ${ }^{7}$, Boby Agus Yusmiono ${ }^{8}$, \\ Hendri Gunawan ${ }^{9}$, Riswan Aradea ${ }^{10}$ \\ 1Universitas PGRI Palembang. Email: neta obyta@yahoo.com \\ 2Universitas PGRI Palembang. Email: dianawidhi72@gmail.com \\ 3Universitas PGRI Palembang. Email: ermayulaini74@gmail.com \\ 4Universitas PGRI Palembang. Email: vhpratiwi@gmail.com \\ 5Universitas PGRI Palembang. Email: ida954321@gmail.com \\ 6Universitas PGRI Palembang. Email: chandrakurniawan79@gmail.com \\ 7Universitas PGRI Palembang. Email: januardibkl@gmail.com \\ 8Universitas PGRI Palembang. Email: boby.yusmiono@yahoo.com \\ ${ }^{9}$ Universitas PGRI Palembang. Email: jayasampurna85@gmail.com \\ 10Universitas PGRI Palembang. Email: riswanaradea@gmail.com
}

\begin{abstract}
The purpose of community service activity is to instill the spirit of "Entrepreneurship in a school environment especially on students in SMA PGRI 4 Palembang". The material is delivered by dividing participants into two classes. The speaker who delivered the material was FKIP lecturer from Palembang PGRI University. After explaining the material by the speakers, participants were asked to carry out entrepreneurship practices. The result of this activity as interest and knowledge of participants about entrepreneurship are increases.
\end{abstract}

Keywords: Entrepreneurship, knowlegde, school environment.

\begin{abstract}
ABSTRAK
Tujuan kegiatan pengabdian kepada masyarakat ini adalah untuk menanamkan jiwa "Enterpreneurship dalam lingkungan sekolah terutama pada siswa di SMA PGRI 4 Palembang”. Materi disampaikan dengan cara membagi peserta menjadi dua kelas. Narasumber yang menyampaikan materi adalah dosen FKIP universitas PGRI Palembang. Setelah penjelasan materi oleh narasumber, peserta diwajibkan untuk melakukan praktik kewirausahaan. Hasil kegiatan ini menunjukkan bahwa animo dan pengetahuan peserta tentang kewirausahaan meningkat.
\end{abstract}

Kata Kunci: Kewirausahaan, pengetahuan, lingkungan sekolah.

\section{PENDAHULUAN}

Pendidikan di Indonesia masih menerapkan hal-hal teori saja, namun tidak menerapkannya dalam kehidupan sosial dan mampu memecahkan berbagai persoalan yang dihadapi mereka sehari-hari. Pendidikan yang tepat diterapkan di Indonesia adalah pendidikan yang beorientasi jiwa kewirausahaan yaitu jiwa yang berani dan mampu menghadapi masalah serta mencari solusinya sendiri tanpa bergantung dengan 
orang lain. Salah satu jiwa kewirausahaan yang perlu dikembangkan melalui pendidikan pada anak usia dini adalah kecakapan hidup (life skill).

Berdasarkan standar nasional pendidikan yang menjadi acuan pengembangan kurikulum 2013 pendidikan kewirausahaan juga termasuk dalam materi yang harus diajarkan dan dikuasai serta direalisasikan oleh peserta didik dalam kehidupan seharihari. Permasalahannya, pendidikan kewirausahaan di sekolah selama ini baru menyentuh pada tingkatan pengenalan norma atau nilai-nilai, dan belum pada tingkatan internalisasi dan tindakan nyata dalam kehidupan sehari-hari. Di samping itu, berlakunya sistem desentralisasi berpengaruh pada berbagai tatanan kehidupan, termasuk pada manajemen pendidikan yaitu manajemen yang memberi kebebasan kepada pengelolaan pendidikan. Adanya kebebasan dalam pengelolaan pendidikan diharapkan mampu menemukan strategi pengelolaan pendidikan yang lebih baik sehingga mampu menghasilkan output pendidikan yang berkualitas baik dilihat dari kualitas akademik maupun non akademik. Kualitas akademik yang dimaksud adalah kualitas peserta didik yang terkait dengan bidang ilmu, sedangkan kualitas non akademik berkaitan dengan kemandirian untuk mampu bekerja di kantor dan membuka usaha/lapangan kerja sendiri. Dengan kata lain lulusan pendidikan diharapkan memiliki karakter dan perilaku wirausaha yang tinggi. (Kemendiknas, 2010).

Menurut Aulidia (2005) adalah membudayakan dan memasyarakatkan wirausaha di Indonesia melalui institusi pendidikan. Pendidikan di sini bisa berupa formal (SD, SMP, SMA, dan Perguruan Tinggi) maupun informal (keluarga). Membangun dan membentuk budaya wirausaha dapat dilakukan mulai dari usia dini. Siswa hendaknya kreatif dan memiliki jiwa interprenership sehingga kelak, apabila lulus nanti memiliki keterampilan dibidang usaha

Instruksi Presiden No. 4 Tahun 1995 tanggal 30 Juni 1995 tentang Gerakan Nasional Memasyarakatkan dan membudayakan Kewirausahaan setidaknya bisa menjadi pijakan untuk membentuk mental kewirausahaan bagi generasi penerus bangsa. Pendidikan kewirausahaan perlu dikembangkan sejak dini, hal ini cukup beralasan agar Indonesia dapat mencetak generasi penerus yang siap dengan tantangantantangan ekonomi di masa mendatang. Pendidik adalah agen of change yang diharapkan mampu menanamkan ciri-ciri, sifat dan watak serta jiwa kewirausahaan atau jiwa entrepreneurship bagi siswanya. Di samping itu, jiwa entrepreneur juga sangat diperlukan bagi seorang pendidik, karena melalui jiwa ini para pendidik akan memiliki orientasi kerja yang lebih efisien, kreatif, inovatif, produk, dan mandiri. Guru perlu menyiapkan anak usia sekolah dasar dengan berbagai strategi untuk menanamkan nilainilai pendidikan kewirausahaan. Guru memiliki tanggung jawab yang besar dalam membentuk karakter anak agar siap dengan tantangan kehidupan dari berbagai aspek bidang, khususnya bidang ekonomi.

Dalam merealisasikan pendidikan yang bermutu, dituntut penerapan program mutu yang fokus pada upaya-upaya penyempurnaan mutu seluruh komponen dan kegiatan pendidikan. Dalam meningkatkan mutu pendidikan untuk meningkatkan SDM adalah: manajemen peningkatan mutu berbasis sekolah (school based management) dimana sekolah diberikan kewenangan untuk merencanakan sendiri upaya peningkatan 
mutu secara keseluruhan. Komponen yang terkait dengan mutu pendidikan antara lain siswa, guru, kurikulum, sarana prasarana, dan masyarakat. Hakim (2012)

Kenyataan saat ini, mutu pendidikan di Indonesia belum mencapai hasil yang diharapkan, sehingga mutu pendidikan masih harus terus ditingkatkan. Peningkatan mutu pendidikan penting untuk dilakukan, karena pendidikan dianggap sebagai suatu investasi yang paling berharga dalam bentuk peningkatan kualitas sumber daya manusia untuk pembangunan suatu bangsa. Departemen Pendidikan Nasional melakukan peningkatan mutu Sumber Daya Manusia dengan melaksanakan pembangunan pendidikan, dengan menetapkan arah melalui Rencana Strategis 20052009 yang salah satu pilar kebijakannya yaitu perluasan akses untuk memperoleh pendidikan pada semua jenis dan jenjang pendidikan termasuk Sekolah Menengah Kejuruan (SMK). Pada dasarnya tujuan Sekolah Menengah Kejuruan adalah menghasilkan tenaga siap kerja yang terampil dan mampu bersaing di dunia usaha maupun dunia industri. Hal tersebut didukung dikeluarkannya kebijakan pemerintah dengan memperbanyak jumlah SMK. Hal tersebut dimaksudkan untuk mempercepat pertumbuhan sumber daya manusia tingkat menengah yang siap kerja, cerdas dan kompetitif yang pada akhirnya akan mendukung pertumbuhan ekonomi nasional.

Menurut Zimmerer \& Scarbrough (2011) "kewirausahaan adalah orang yang menciptakan bisnis baru dengan mengambil risiko dan ketidakpastian demi mencapai keuntungan dan pertumbuhan dengan cara mengidentifikasi peluang dan menggabungkan sumber daya yang diperlukan untuk mendirikannya". wirausaha tidak mencari risiko, mereka mencari peluang (Druker dalam Osborne, 2014).

Menurut Savary (2017), yang dimaksud dengan 'entrepreneur' ialah orang yang membeli barang dengan harga pasti, meskipun orang itu belum tahu dengan harga berapakah barang (atau guna ekonomi) itu akan dijual.

Pencapaian Target yang diharapkan dalam Pengabdian Kepada Masyarakat (PkM) Enterpreneurship di Lingkungan Sekolah pada SMA PGRI 4 Palembang : Guru dan Siswa SMA PGRI 4 Palembang dapat Mengetahui pentingnya belajar kewirausahaan, motivasi, kepemimpinan, pengelolaan manajemen keuangan, analisa keuangan, pengembangan kreativitas, penerapan landasan hukum, tips dan trik dalam menjalankan kewirausahaan.

\section{METODE PELAKSANAAN}

Kegiatan Pengabdian kepada Masyarakat ini adalah dosen-dosen yang terdapat pada FKIP Universitas PGRI Palembang yang berjumlah sepuluh orang Dosen Tetap Yayasan (DTY), dilaksanakan dengan rincian sebagai berikut:

\section{Tahap Persiapan}

Melakukan survey dan wawancara dengan guru dan siswa SMA PGRI 4 Palembang, sehingga menemukan masalah yang berkenaan dengan menumbuhkan jiwa Enterpreneurship sedini mungkin, kemudian dilanjutkan dengan izin melakukan PkM berikut penentuan jadwal pelaksanaan PkM itu sendiri. 


\section{Tahap Pelaksanaan}

Pelaksanaan PkM dilakukan sebagaimana berikut di bawah ini:

1. Konsep PkM adalah penyuluhan tentang Entrepreneurship dalam Lingkungan Sekolah Di SMA PGRI 4 Palembang

2. Peserta berjumlah 30 orang yang terdiri dari Kelas $\mathrm{X}$ ada 10 orang, Kelas XI $=10$ orang, Kelas XII = 10 orang

3. Team melibatkan beberapa mahasiswa dari FKIP untuk membantu pelaksanaan kegiatan PkM

4. Kegiatan Penyuluhan dilaksanakan di dua kelas SMA PGRI 4 Palembang yang beralamat di Jalan Taqwa Mata Merah Kelurahan Sei. Selincah Kecamatan Kalidoni Palembang, Sumatera Selatan Kamis, 29 November 2018, pukul 13.00 sampai dengan selesai

5. Tm Menunjukkan hasil-hasil karya handmade atau produk-produk yang merupakan hasil dari kewirausahaan

6. Penyuluhan dilakukan dengan metode ceramah interaktif tentang Entrepreneurship yang bisa mulai dirintis dan dikembangkan oleh siswa, pembagian materi sebagai berikut:

a. Kelompok I, berkenaan dengan materi, 1) Menanamkan minat berwirausaha , 2) Motivasi berwirausaha dikalangan Siswa, 3) Kepemimpinan bagi Wirausaha di Lingkungan Sekolah, 4) Manajemen Keuangan Kewirausahaan dilihat dari Analisis Tititk Impas (Studi Kasusu pada Warung Martabak Ibu Rosida di Daerah Sungsang III Kabupatem Banyuasin Sumatera Selatan, 5) Peraturan Pemerintah tentang Pentingnya Berwirausaha bagi Pendidikan Sekolah

b. Kelompok II, berkenaan dengan materi, 1) Evaluasi Kbijakan Pemerintah terhadap Perkembangan Industri Kreatif, 2) Analisis Laporan Keuangan Bazar Kewirausahaan Produk Kreatif Limbah K5PBB, 3) Berwirausaha dengan Limbah Organik dan Non Organik di Lingkungan Sekolah, 4) Unit Usaha Sekolah, Guru, dan Teman Sebagai Media Pembelajaran Berwirausaha, 5) Project Base Learning sebagai Wahana Latihan Berwirausaha

7. Team memberikan kesempatan bagi siswa untuk berdiskusi berkenaan dengan materi yang diberikan

\section{Tahap Hasil}

Team melakukan analisis terhadap proses pelaksanaan dan manfaat kegiatan PkM di SMA PGRI Palembang

\section{HASIL DAN PEMBAHASAN}

Kegiatan Pengabdian kepada Masyarakat ini diikuti oleh Sepuluh Dosen Tetap Yayasan Fakultas Keguruan dan Ilmu Pendidikan Universitas PGRI Palembang bersama enam orang mahasiswa, mengajukan perizinan di SMA PGRI 4 Palembang yang beralamat di Jalan Taqwa Mata Merah Kelurahan Sei. Selincah Kecamatan Kalidoni Palembang, Sumatera Selatan, untuk pelaksanaan Pengabdian kepada Msyarakat dan 
berhasil disetujui dan dilaksanakan pada hari Kamis, 29 November 2018, pukul 13.00 sampai dengan selesai

\section{Tahap Persiapan}

Untuk lebih efektif dalam pengampaian materi, dimana masing-masing tim PkM hanya diberi waktu pemaparan selama 15 menit, sehingga tim PkM bekerja sama dengan Kepala Sekolah SMA PGRI 4 Palembang, Bapak Drs. Risman, membagi menjadi dua kelas yang masing-masing kelas berisikan sepuluh orang guru dan lima belas orang siswa SMA PGRI 4 Palembang untuk lima orang tim PkM.

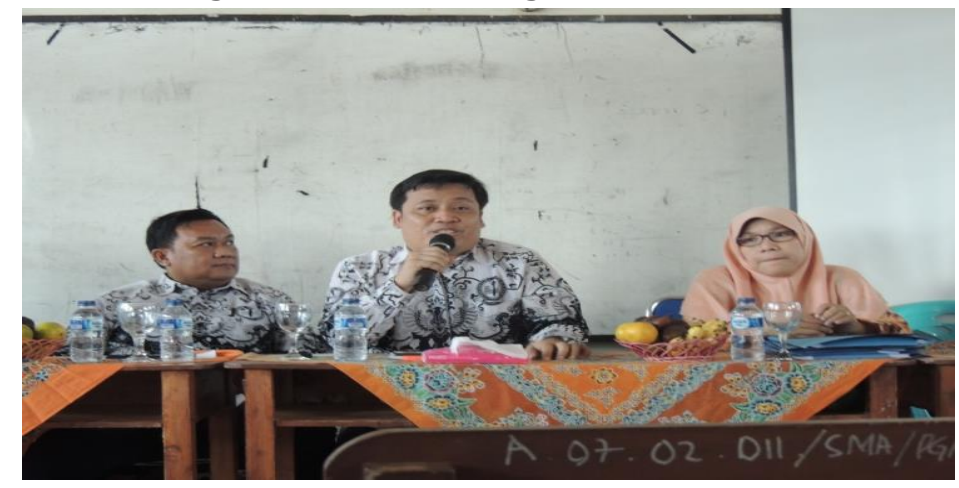

Gambar 1. Tahap persiapakan PKM

\section{Tahap Pelaksanaan}

Kegiatan pengabdian kepada masyarakat yang dilakukan oleh delapan dosen Program Studi Pendidikan Akuntansi, Program Studi Pendidikan Geografi dan Program Studi Pendidikan Sejarah di Fakultas Keguruan dan Ilmu Pendidikan di Universitas PGRI Palembang ini telah terlaksana dengan baik dan selesai sebagaimana waktu yang telah ditentukan. Rangkaian acara kegiatan ini dimulai dari salah satu dosen melakukan pembukaan dan pengantar serta arahan maksud dari tujuan adanya kegiatan pengabdian masyarakat yang dilakukan di Universitas PGRI Palembang. Selanjutnya dosen secara bergiliran memberikan materi sesuai dengan temanya masing-masing.

Kesempatan diskusi dibuka setelah masing-masing tim PkM telah menyampaiakan materinya, dan pada session inilah terlihat animo para peserta cukup tinggi, karena perhatian mereka terpusat dengan materi yang disampaikan sehingga banyak menimbulkan pertanyaan demi memperdalam pengertian dan pemahaman mereka tentang kewirausahaan.

Materi pertama di ruang kelas pertama atau kelompok pertama diawali oleh dengan penjelasan tentang apa itu Menanamkan Minat Berwirausaha oleh Januardi, S.Pd., M.Si sedangkan di kelas kedua atau kelompok kedua, materi pertama diawali dengan penjelasan Evaluasi Kebijakan Pemerintah terhadap Perkembangan Industri Kreatif oleh Chandra Kurniawan, SE, M.Si. 


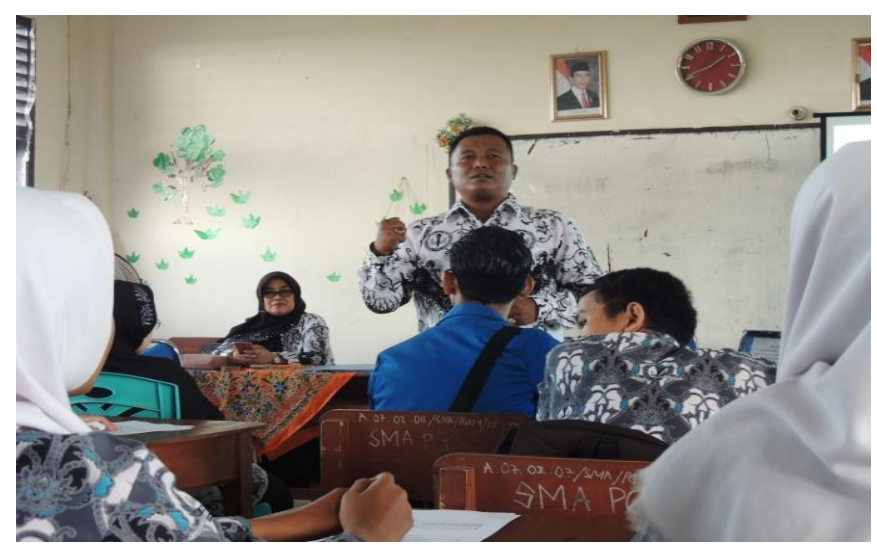

Gambar 2. Pemberian materi pertama PKM

Materi kedua di ruang kelas pertama oleh Riswan Aradea, S.P.MM yang berkenaan dengan materi Motivasi Berwirausaha Dikalangan Siswa sedangkan di kelas kedua atau kelompok kedua, Ibu Neta Dian Lestari, S.Pd., M.M menyampaiakan materi berkenaan dengan Analisis Laporan Keuangan Bazar Kewirausahaan Produk Kreatif Limbah K5PBB.

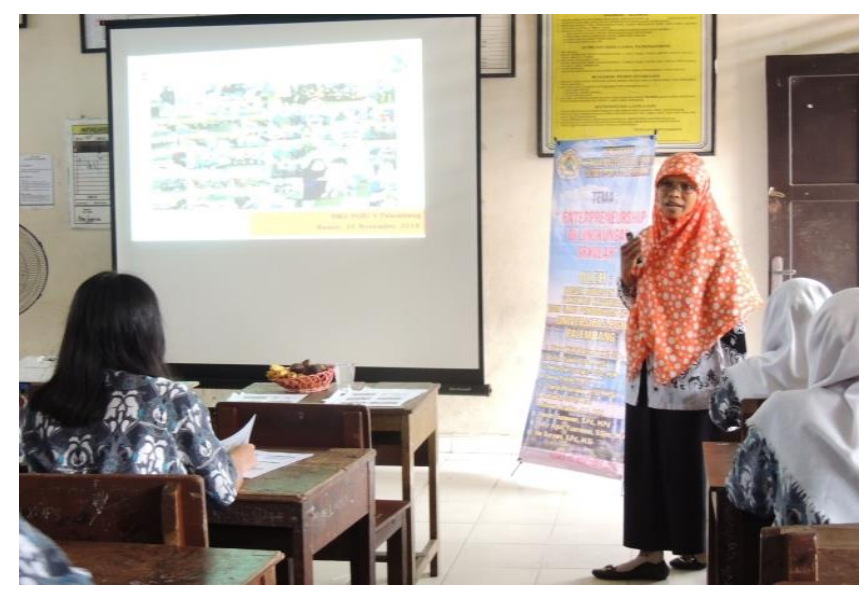

Gambar 3. Pemberian materi kedua PKM

Ibu Erma Yulaini, S.Pd, M.Si dalam hal ini sebagai dosen pemateri ketiga di kelas pertama menyampaikan materi berkenaan dengan Kepemimpinan bagi wirausaha di Lingkungan, sedangkan untuk penyampaian materi ketiga oleh Bapak Boby Agus Yusmiono, S.Sos, M.A berkenaan dengan Berwirausaha dengan Limbah Organik dan Non Organik di Lingkungan Sekolah.

Materi keempat di ruang kelas pertama atau kelompok pertama disampaikan oleh Ibu Diana Widhi Rachmawati, S.IP., MM yang menyampaikan tentang Manajemen Keuangan Kewirausahaan dilihat dari Analisis Titik Impas (Studi Kasus pada Warung Martabak Ibu Rosida di daerah Sungsang III Kabupaten Banyuasin Sumatera Selatan, sedangkan di kelas kedua atau kelompok kedua, penyampaina materi berkenaan dengan Unit Usaha Sekolah, Guru, dan Teman Sebagai Media Pembelajaran Berwirausaha bagi Siswa disampaikan oleh Hendri Gunawan, S.Pd. M.Pd

Pemamaparan materi ditutup dengan penyampaian materi terakhir di kelas pertama oleh Ibu Ida Suryani, S.Pd, M.Si dengan judul Peraturan Pemerintah tentang 
Pentingnya Berwirausaha bagi Pendidikan Sekolah, sedangkan di kelas kedua, penyampaian materi ditutup dengan judul materi Project Base Learning sebagai Wahana Latihan Berwirausaha oleh Ibu Nova Pratiwi, M.Pd

\section{Tahap Hasil}

Tingkat pemahaman mereka semakin bertambah karena banyak sektor kewirausahaan yang dapat mereka pelajari dan suatu ketika mereka rintis demi masa depan mereka nanti, sesuai dengan keinginan pemerintah saat ini.

\section{SIMPULAN}

Pengabdian kepada masyarakat ini dapat meningkatkan dan membangkitkan rasa profesionalisme dosen di lingkungan program studi Pendidikan Akuntansi Fakultas Keguruan dan Ilmu Pendidikan Universitas PGRI Palembang dan meningkatkan pengetahuan dan pemahaman peserta didik khususnya guru dan siswa di lingkungan SMA PGRI 4 Palembang. Harapa dari kegiatan ini adalah dapat terus dilaksanakan secara berkelanjutan guna memberikan pengetahuan dan menumbuhkan minat berwirausaha baik guru dan siswa di SMA PGRI 4 Palembang.

\section{DAFTAR RUJUKAN}

Hakim, D. (2012). Kendali Mutudan Kinerja Guru Pendidikan Agama Islam di SDIT ArRuhul Jadid Jombang Penelitian Hibah Internal Dosen di Unipdu tanggal 3 Maret 2012.

Kementrian Pendidikan Nasional. (2010). Pengembangan Pendidikan Budaya dan Karakter Bangsa, Bahan Pelatihan Penguatan Metodologi Pembelajaran Berdasarkan Nilai-Nilai Budaya untuk Membentuk Daya Saing dan Karakter Bangsa. Jakarta: Badan dan Penelitian Pusat Kurikulum Kementrian Pendidikan Nasional.

Osborne, D. \& Gaebler T. (2014). Mewirausahakan Birokrasi. Jakarta: PPm Manajemen.

Savary. (2017), Kamus Dagang. Retrieved from https://brainly.co.id

Zimmerer, T. W. \& Scarbrough, N. M. (2011). Kewirausahaan. Yogyakarta: CV Andi Offset 
80 J-Abdipamas, Vol. 3, No. 2 Oktober, 2019 